\title{
Bulk Soil Properties as the Determinants of Soil Surface Shear Strength of Puddled Lowland Rice Soils of Sri Lanka affected by Weed Controlling methods
}

\author{
G.V.T.V. Weerasooriya ${ }^{*}$, D.N. Jayatissa ${ }^{1}$ and M. Rambanda ${ }^{2}$ \\ Postgraduate Institute of Agriculture \\ University of Peradeniya \\ Sri Lanka
}

\begin{abstract}
Soil shear strength (SS) is an important parameter for designing appropriate farm machinery. This study was aimed to estimate the surface SS of lowland puddled rice soils in Sri Lanka through the assessment of bulk soil parameters including soil moisture content (MC), bulk density (BD), soil texture and organic matter content (OM) under different weed control methods. Vane shear tester was used to measure the surface SS. All soil parameters were measured throughout the Maha Season of 2013/14, with four treatments; (1) bare lowland, (2) no weed control, (3) chemical weed control and (4) weed managed by "Asakura" wooden clog in three replicates. After identifying the effect of weed control method, measured values were evaluated to identify the suitable determinants to explain the variation of surface SS and ultimately built up their relationships. Results reveled that measured SS significantly varied with weed control method and time. Bulk soil properties did not significantly vary with weed control method (excluding clay \%) and showed significant temporal variation (excluding sand\% and $O M$ ) at $p<0.05$. Surface SS showed a significant relationship with $B D$ and $M C$ at 0.05 probability level, it could be estimated by $107.053-1.06 \mathrm{MC}-42.738 \mathrm{BD}$ in chemical weed control fields and other fields by $110.643-1.06 \mathrm{MC}-42.738 \mathrm{BD}$. It is suggested to conduct future studies including depth variation of SS, weed and plant growth parameters which may provide sound information to improve this finding.
\end{abstract}

Keywords: Bulk soil parameters, Surface shear strength, Weed controlling methods

\section{INTRODUCTION}

Rice is the staple food of the inhabitants of Sri Lanka and cultivated as a wetland crop in all the districts. There are two major cultivation seasons namely; Yala and Maha which depend on the two monsoons. The net extent, average yield and production of paddy were 520,608 ha, 4,222 kg/ha and 2,235,851 MT in the Maha season (2013/14), and the corresponding figures in the Yala season (2014) were 272,399 ha, 4,204 $\mathrm{kg} / \mathrm{ha}$ and 1,144,929MT respectively (DCS, 2015).

When seeking solutions for the problems associated with the rice cultivation in Sri Lanka, (such as; drudgery, higher production cost, low quality of produce, low cropping intensity

\footnotetext{
${ }^{1}$ Department of Agricultural Engineering, Faculty of Agriculture, University of Peradeniya, Sri Lanka.

2 Sub Campus, University of Peradeniya, Mahailluppallama

* Corresponding author: gvtvw@agri.rjt.ac.lk
} 
and the labour scarcity) mechanization seems to be a viable strategic option (Tilakaratna and Tilakaratna, 2003).

Though several tools and machineries have been introduced to perform various operations in paddy cultivation, most of them are not popularized among Sri Lankan farmers due to some defects and low adaptability to the local conditions (Rathnayaka et al., 2011). Hence farm machinery designers have to pay broad attention in designing appropriate farm machinery which suitable to the prevailing agro-climatic, ecological and socio economic aspects (FMRC, 1991). Since most of the farm machineries use in paddy cultivation has to work in puddled soil condition, it is very important to study the puddled soil condition.

The soil-crop-machinery interaction studies give paramount importance in providing design parameters such as soil strength, which is useful to determine the workability of farm machinery (IRRI, 1994), draft (Lipiec and Hatano, 2003) and power (Hillel, 2004) requirements etc. Soil strength is defined as the capacity of a soil to resist or endure an applied force or soils' load-bearing capacity (Ghildyal and Tripathi, 1987). Soils are subjected to two kinds of deforming stresses: (a) the normal stress (load) associated with compression and (b) tangential stress causing shear (Bhagat, 2003). Compression strength of the puddled lowland paddy soils in Sri Lanka was evaluated and estimated by Weerasooriya et al. (2015), using bulk soil properties as determinants. Though few attempts had been taken to measure the shear strength (SS) (Rathnaweera et al., 2010) no attempt had been made to estimate the SS of lowland puddled paddy soils of Sri Lanka.

Measurement of soil SS is not easy, as it is a highly variable property which often change during the process of measurement (Hillel, 1971). The principle direct shear devices, which have been used to measure the shear strength of agricultural soils, are the grouser plate, translational shear box, NIAE torsional shear box, vane shear tester, shear graph and an annular torsional shear apparatus (Johnson et al., 1987). Comparisons of various devices and methods, (Osman, 1964; Bailey and Weber, 1965) and Dunlap et al. (1966), indicate that translational shear box, triaxial test, annulus device, the shear graph, and NIAE shear box give different values of confusing factor $(C)$ and shear stress $(\phi)$. However the vane cone device developed by Young and Youssef (1978) may be very applicable to agricultural soil machine system since it creates both a soil shear failure and a penetration into the soil when compared with other methods (Johnson et al., 1987).

A direct and in-situ method for assessing the soil shear strength is to use a vane shear tester which consists of plate, handle and a set of vane. It gives quantitative reading on maximum shearing torque, which could be converted to the soil SS (Burns et al., 2009). However it is not adequate for accurate assessment of overall soil SS because, assessing by one direct index may mislead the results and give relatively great spatial variation due to the point measurement (Hillel, 1971). Hence Eudoxie et al. (2012) suggested using bulk soil parameters for overall estimation of soil strength. Soil moisture content, bulk density, soil compressibility, soil structure, soil texture and organic matter content are the potential nonpoint (bulk) soil indices of soil strength (IRRI, 1994). On other hand, surface SS is highly varied with inter-cultivation activities such as weeding. Hence it is very important to evaluate SS under different weed control methods.

Therefore, this study aimed to estimate the surface SS of lowland puddled rice soils in Sri Lanka through the assessment of bulk soil parameters in different weed control methods. The specific objectives of this study were; (1) measure variation of soil surface SS and potential bulk soil parameters in different weed control method (2) Identify the effect of weed control 
method on measured soil properties (3) identify the suitable determinant to explain the surface SS variation and (4) build up the relationships between them. It was hypothesized that these significant relationships could be utilized to asses SS of the puddled lowland rice soils in Sri Lanka under the respective weed controlling method.

Soil bulk properties including soil moisture content (MC), bulk density (BD), soil texture and organic matter content $(\mathrm{OM})$ were evaluated in this study due to the limitation of available laboratory facilities and measurability.

\section{METHODOLOGY}

This experiment was conducted during the 2013/14 "Maha" season, from November 2013 to March 2014, in Faculty of Agriculture, Rajarata University of Sri Lanka, Puliyankulama, Anuradhapura (NCP). This area is located in latitudes; $8^{0} 16^{\prime}-8^{0} 22^{\prime} \mathrm{N}$ and longitudes; $80^{\circ}$ $20^{\prime}-80^{\circ} 30^{\prime} \mathrm{E}$ in the $\mathrm{DL}_{1 \mathrm{~b}}$ agro ecological region of Sri Lanka (Punyawardane et al., 2003). Major soils found in this area are Reddish Brown Earths (Rhodustalfs) and Low Humic Gley (Tropaqualfs) which is the hydromorphic association of the Reddish Brown Earths. Madawachiya series is the dominant soil series found in this area (Mapa et al., 2009).

\section{Experimental design}

As per the Randomized Complete Block Design (RCBD), four treatments which included different weed control practices and three replicates were established on $8 \times 5 \mathrm{~m}^{2}$ plots. Four treatments were; $\mathrm{T}_{1}-$ Control (bare land. It was neither cultivated nor weed controlled), $\mathrm{T}_{2}-$ No weed controlling (paddy was grown and no weeds were controlled), $\mathrm{T}_{3}-$ Chemical weed controlling (paddy was grown and weeds were controlled by chemical application), and $\mathrm{T}_{4}-$ Weeds were managed with modified manual "Asakura" wooden clog. This device first pushes the weeds flat on the surface and then pushes those about $10 \mathrm{~cm}$ deep into the mud due to the function of shoe (Jayatissa and Wickramasinghe, 2010).

\section{Land preparation, crop establishment and management}

A paddy field which extended up to $560 \mathrm{~m}^{2}$ in one basin was selected as the experimental site. Boundaries of experimental site were demarcated by making bunds. Primary land preparation was done after impounding water with two ploughings up to $30 \mathrm{~cm}$ by fourwheel tractor coupled disk plough and the tine tiller, respectively. Harrowing, fine leveling and puddling were done by two-wheel tractor coupled rotovator and leveling board. As per the DOA recommendation, basal fertilizer dressing was applied just before the leveling. Plots were demarcated by placing lateral $(25 \mathrm{~cm})$ and longitudinal $(30 \mathrm{~cm})$ drainage channels. $1 \mathrm{~m}$ $\mathrm{X} 1 \mathrm{~m}$ grid system established by wooden pegs was used to identify the proper sampling places by avoiding sampling bias and overlapping throughout the experimental period.

Bg 358 (SAMBA) 3.5 months variety was used as the seed paddy. After two weeks in the wet bed nursery, seedlings were established manually in the well-puddled field (two plants/hole) with the spacing of $12.5 \mathrm{~cm} \mathrm{X} 24 \mathrm{~cm}$, as discussed by Jayatissa and Wickramasinghe (2010), to facilitate the use of modified "Asakura" wooden clog in $\mathrm{T}_{4}$, maintaining the DOA recommended plant density. 
After the field establishment, a proper irrigation schedule was carried out with five to seven days irrigation intervals and fertilizer application was done as per the DOA recommendation.

\section{Field measurement and sampling}

Coordinates of the random sampling places were drawn by the Microsoft Excel 2007 software and field sampling places were identified by the established grid system. Data were collected throughout the season (15 weeks) with one week sampling intervals.

Surface shear strength was measured by using Vane Shear Tester. This equipment placed on the respective sampling point and vanes were driven in to the soil. Then arm was rotated with the rate of $15^{\circ}$ per minutes until the equipment shows a constant reading. Reading was taken as the shear torque $(\mathrm{Nm})$ directly from its own reading plate and it was converted in to shear strength $\left(\mathrm{Nm}^{2}\right)$ using equation No: 01 and 02 (Burns et al., 2009). Disturbed and undisturbed soil samples were collected using soil auger and core sampler, respectively, for soil analysis.

$$
\begin{aligned}
& K_{s \text { haft }}=\left[\frac{\pi D_{s}^{3}}{2}\left(\frac{h}{D_{s}}-\frac{1}{6}\right)+\frac{\pi D^{3}}{2}\left(\frac{H}{D}+\frac{\mathbf{1}}{3}\right)\right] \\
& \tau=\frac{T}{K_{s h a f t}}
\end{aligned}
$$

Where,

$\mathrm{T}$ - Calculated Shear Stress in Pascal

$\mathrm{K}_{\text {shaft }}-$ Revised Vane Shear Constant in $\mathrm{m}^{3}$

$\mathrm{D}_{\mathrm{s}}$ - Shaft Diameter in $\mathrm{m}$

$\mathrm{h}$ - Immersion Depth of the Vane in $\mathrm{m}$
$\mathrm{T}$ - Measured Torque in $\mathrm{Nm}$

D - Shear Vane Diameter in $m$

$\mathrm{H}$ - Shear Vane Height in $\mathrm{m}$

(Burns et al., 2009)

\section{Laboratory analysis}

While undisturbed samples were used to determine BD and MC; the disturbed samples were used to analyze soil texture and OM content after air drying, crushing and screening through $2 \mathrm{~mm}$ and $0.5 \mathrm{~mm}$ sieves, respectively. Soil texture and OM content were determined only at the beginning ( 1 week after transplant/WAT) and at the end (15 WAT) of this study.

Standard soil analyses were conducted. Soil MC was determined by gravimetric method (Majumdar and singh, 2002). The core sampler $(\varnothing=50 \mathrm{~mm}$ ) was used to determine the BD of the soil (Singh, 1980). As discussed by Dharmakeerthi (2007), soil texture was determined by pipette method. As stated by Wickramasinghe (2007), OM content was determined by Walkly and Black wet oxidation method with the empirical factor 2 for the conversion of carbon to OM (Nelson and Sommers, 1982).

\section{Data analysis}

Significant variables at $\mathrm{p}<0.05$ was selected by fitting analysis of variance (ANOVA) models using GLM procedure of SAS software. Least Square Mean (LSMEANS) separation was used to separate means of significant variables. Effects of determinants on SS were identified by fitting linear regression models. 


\section{RESULTS AND DISCUSSION}

Significantly affected soil properties by treatment (weed controlling method) and time (WAT) at $\mathrm{p}<0.05$ and regression statistics of related soil properties are shown in tables 1 and 2 , respectively. The temporal variation of soil properties and their relationships are illustrated in figures 1 and 2, respectively.

\section{Soil properties}

Surface SS significantly varied with weed controlling method (treatment) and the time/weeks after transplant (WAT) at $\mathrm{p}<0.05$, where the significantly lowest SS value $(19.255 \mathrm{kPa})$ was recorded in $\mathrm{T}_{3}$; (chemical weed controlling). There was no significant difference among the other treatments (average; $23.238 \mathrm{kPa}$ ). This may be the result of loosening the soil structure by the chemical reaction and the lower root density in surface soil layer due to the lower weed count in $T_{3}$. As illustrated in Fig. 1, average $S S$ of $T_{1}, T_{2}$ and $T_{3}$ increased with the time from lowest at the beginning $9.959 \mathrm{kPa}$ (1-2 WAT) to the highest at the harvest $49.243 \mathrm{kPa}$ (15 WAT) with slight fluctuations due to irrigation practices and rainfall $(\overline{\mathrm{x}}=23.46 \mathrm{kPa}, \mathrm{s}=$ 11.325). SS of $\mathrm{T}_{3}$, varied from the lowest $9.959 \mathrm{kPa}(1-3 \& 5 \mathrm{WAT})$ to the highest 39.837 (15 WAT) by showing similar pattern as in $\mathrm{T}_{3}$ with lower mean $(\overline{\mathbf{x}}=19.365 \mathrm{kPa}, \mathrm{s}=9.062)$. However this deviation was observed after 3 WAT where chemical was applied. This also confirmed the previous determination on soil loosening due to chemical reaction. As discussed by Onyelowe and Chibuzor (2013), pattern of SS variation depends on the MC (drainage) variation which showed the significant correlation with $\mathrm{SS}$ in $\mathrm{T}_{3}(\mathrm{r}=-0.69)$ and other treatments $(r=-0.76)$. Lower SS values was recorded at beginning due to higher MC and loose arrangement of soil particles and then it increased as soil particles settled, which is in agreement with Bhagat (2003), and Onyelowe and Chibuzor (2013).

In addition to the temporal variation, $\mathrm{MC}$ of the experimental site varied with the irrigation pattern and the rainfall. Weed controlling method (treatment) did not significantly affect the MC at $\mathrm{p}<0.05$. The average MC was $27.396 \%$ among different treatments. As illustrated in Fig. 1, MC (37.485\%) was the highest initially (1 WAT) and it declined up to $12.525 \%$ in 12 WAT showing slight fluctuations with the irrigation pattern and rainfall $(\overline{\mathbf{x}}=27.063 \%, \mathrm{~s}=$ 6.909). After 10 weeks, irrigation supply was cut down and the field was prepared for harvesting. Hence drastic MC drop was recorded at 10-12 WAT. Then sudden increment of MC was noted up to $14 \mathrm{WAT}$ due to additional irrigation water supply. After $14 \mathrm{WAT}$, field was prepared for the harvesting by cutting the irrigation water supply again. MC showed the significant correlation with $\mathrm{SS}$ in $\mathrm{T}_{3}(\mathrm{r}=-0.69)$, other treatments $(\mathrm{r}=-76)$. As well BD showed the significant correlation with SS $(r=-0.574)$.

Bulk density (BD) of the surface soil was not significantly affected by the weed controlling method but time at $\mathrm{p}<0.05$. Average BD was $1.45 \mathrm{~g} / \mathrm{cm}^{3}$. As shown in Fig. 1, BD varied throughout the experimental period $\left(\overline{\mathbf{x}}=1.457 \mathrm{~g} / \mathrm{cm}^{3}, \mathrm{~s}=0.093\right)$. As reported by Bhagat et al. (1999) initially lowest BD $\left(1.323 \mathrm{~g} / \mathrm{cm}^{3}\right.$ at $\left.1 \mathrm{WAT}\right)$ is due to the submergence prior to tillage and it increased with the time up to $1.7 \mathrm{~g} / \mathrm{cm}^{3}$ (12 WAT) which recorded as the highest, when the puddled soils shrink due to desiccation. As indicated by Eudoxie et al. (2012), this may be due to the MC variation of the field which showed the significant correlation $(r=-0.574)$ at $0.05 \alpha$ level. As discussed by Grossman and Reinsch (2002), this average $\mathrm{BD}$ is in the reference range of agricultural soils. 
By comparing the textural behavior of the initial (1WAT) and the end (15 WAT) of this experiment, silt and clay content showed a significant deference. There was no significant difference on sand fractions at $\mathrm{p}<0.05$. Only, clay content varied with weed controlling pattern and showed the significantly higher clay accumulations in $T_{3}(19.346 \%)$ and $T_{2}$ $(14.709 \%)$ where chemical and no weeding methods were practiced, respectively. However there is no significant difference among them. The significantly lowest and moderately lower clay accumulations were recorded in $\mathrm{T}_{4}(2.268 \%)$ where wooden clogs are utilized and $\mathrm{T}_{1}$ $(8.006 \%)$; control, respectively. The lowest clay content in $\mathrm{T}_{4}$ may be due to disturbance of soil in clog application and higher intensity of erosion. Sand\% (Average $=80.616 \%$ ) and silt $\%$ (Average $=9.923 \%$ ) were not significantly varied with treatment at $\mathrm{p}<0.05$.

There was no significant difference in OM between the start (1 WAT) and the end (15 WAT). Weed controlling pattern also did not significantly affect surface OM $(p<0.05)$. The average OM of surface soil was $0.921 \%$. As reported by Jayatissa and Wickramasinghe (2010), there should be an increase in $\mathrm{OM}$ in $\mathrm{T}_{4}$ where the wooden clog was applied due to weed burring. But, observed time (15 weeks) is not sufficient to reflect that OM increment due to buried weeds and sampling depth did not reach the layer of buried weed.

\section{Relationship between SS and other soil properties}

As illustrated in Fig. 2, MC shows significant linear relationships with $\mathrm{SS}$ in $\mathrm{T}_{3}(\mathrm{~m}=-0.906$ and $\mathrm{c}=43.888)$ and other treatments $(\mathrm{m}=-1.247$ and $\mathrm{c}=57.202)$. BD and MC also show significant linear relationship $(\mathrm{m}=-42.795$ and $\mathrm{c}=89.104)$. As per the regression analysis results shown in Table 2, MC and BD are significantly related with surface SS at $\mathrm{p}<0.05$. Hence they could be utilized to explain variation of surface SS by $107.053-1.06 \mathrm{MC}-$ $42.738 \mathrm{BD}$ in $\mathrm{T}_{3}$ where chemically weed controlled and $110.643-1.06 \mathrm{MC}-42.738 \mathrm{BD}$ for $\mathrm{T}_{1}, \mathrm{~T}_{2}$ and $\mathrm{T}_{4}$. As shown in the Fig. 3, the predicted and measured SS values show higher linear relationships $\left(\mathrm{R}^{2}=0.695\right.$ in $\mathrm{T}_{3}$ and 0.794 in other treatments). As reported by Eudoxie et al. (2012), MC is identified as the determinant of surface soil strength of upland soils and Weerasooriya et al. in (2015); MC and BD are identified as the determinants of surface compression strength of low land pudddled soil. These are partially supportive findings to this result.

Table 1. ANOVA for soil properties (Probability values)

\begin{tabular}{lccccccc}
\hline $\begin{array}{l}\text { Eactors } \\
\text { Source }\end{array}$ & SS & MC \% & BD & $\begin{array}{c}\text { Sand } \\
\text { \% }\end{array}$ & Silt \% & Clay \% & OM \% \\
\hline Treatment & $<0.0102^{*}$ & 0.3030 & 0.2580 & 0.9953 & 0.5746 & $<0.0001^{*}$ & 0.8566 \\
\hline $\begin{array}{l}\text { Time } \\
\text { (WAT) }\end{array}$ & $<0.0001^{*}$ & $<0.0001^{*}$ & $<0.0001^{*}$ & 0.0542 & $0.0034^{*}$ & $<0.0001^{*}$ & 0.9533 \\
\hline
\end{tabular}

*Significant difference at $\mathrm{p}<0.05$

$\mathrm{SS}$ - Shear strength, MC - Moisture content, BD - bulk density, OM - Organic matter content

Table 2. Regression statistics of soil properties

\begin{tabular}{cccc}
\hline Treatment & P Value & Equation & R-square \\
\hline $\mathrm{T}_{3}$ & $<.0001$ & $\mathrm{SS}=107.053-1.06 \mathrm{MC}-42.738 \mathrm{BD}$ & 0.7047 \\
\hline $\mathrm{T}_{1}, \mathrm{~T}_{2}$ and $\mathrm{T}_{4}$ & $<.0001$ & $\mathrm{SS}=110.643-1.06 \mathrm{MC}-42.738 \mathrm{BD}$ & 0.7047 \\
\hline
\end{tabular}




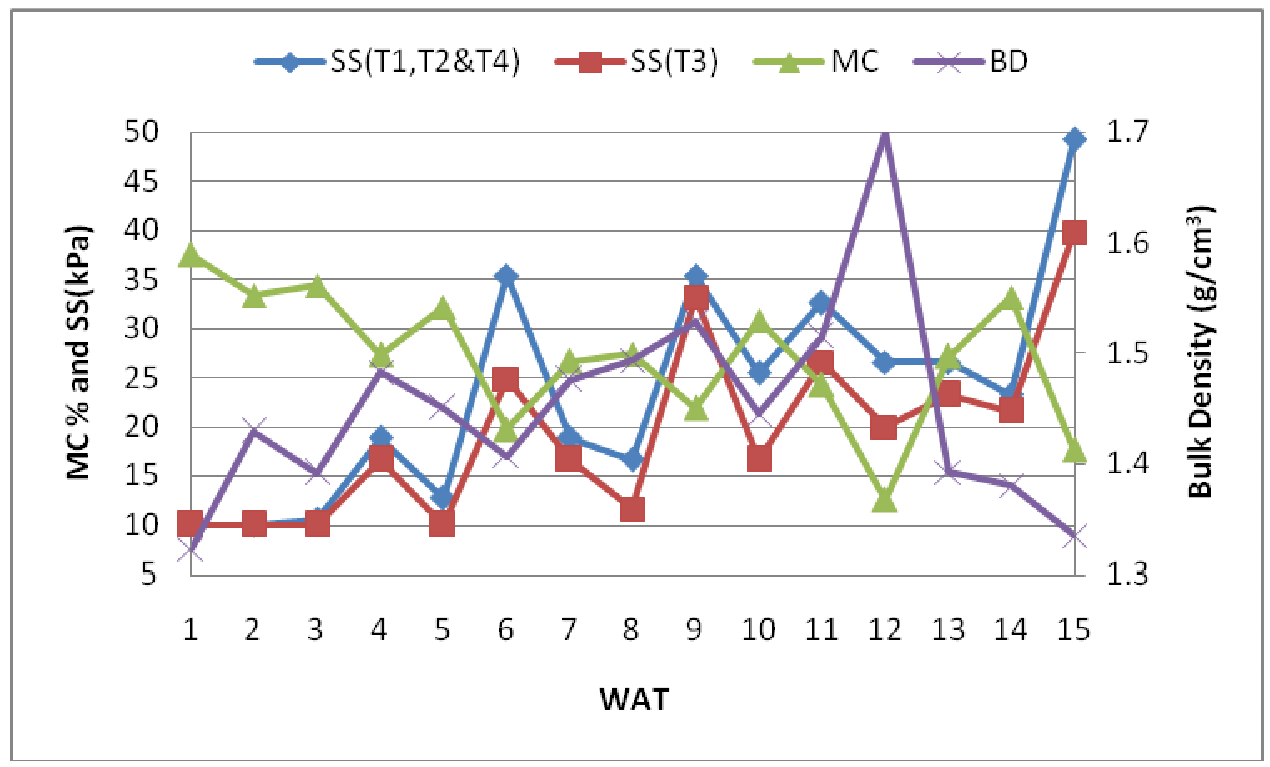

Fig.1. Temporal variation of soil properties in different weed control methods

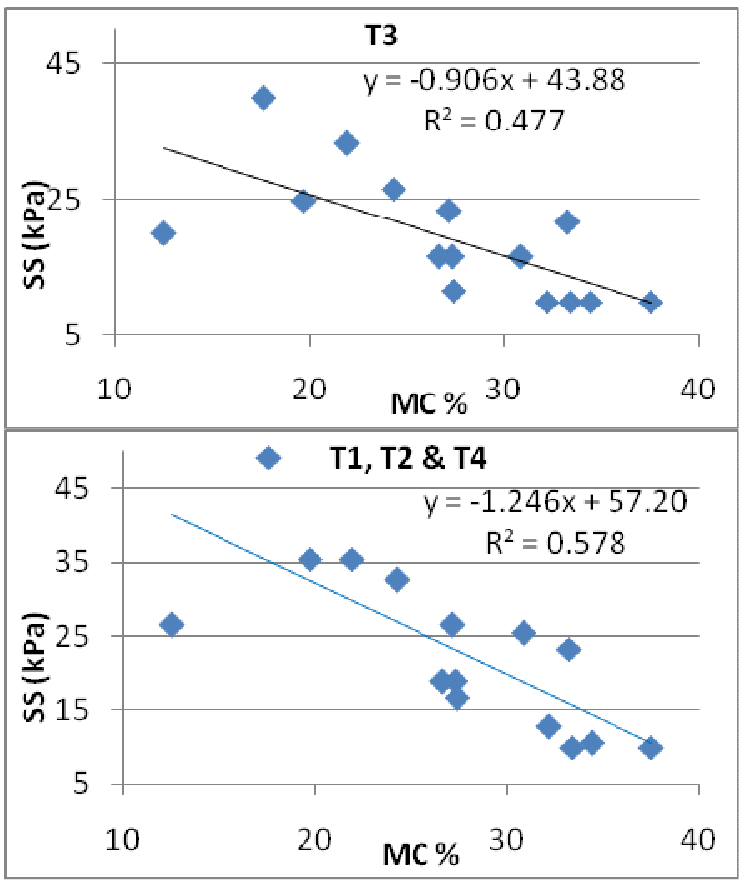




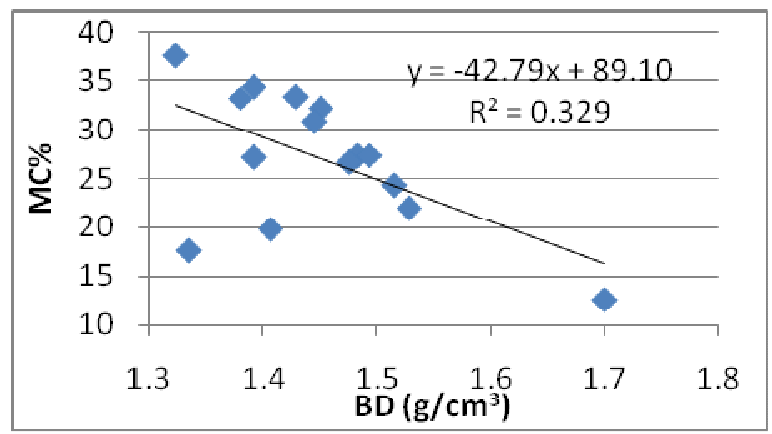

Fig.2. Relationships between soil properties

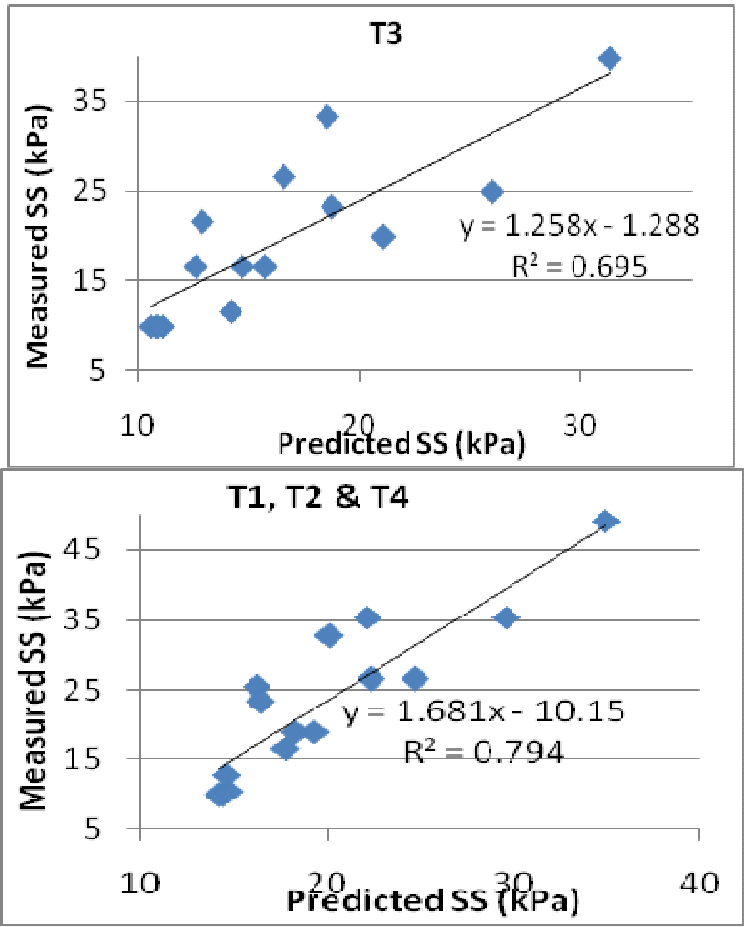

Fig.3. Predicted Vs measured SS values in different weed control methods

\section{CONCLUSION}

The surface shear strength (index property) varied with the weed controlling method and bulk soil properties (except clay \%) did not vary with the weed controlling method. Measured soil parameters; excluding sand $\%$ and organic OM, showed temporal variation. Bulk density and moisture content could be utilized to determine the overall surface shear strength of puddled lowland rice soils in Sri Lanka by 107.053 - 1.06 MC - 42.738 BD in chemical weed controlling fields and by $110.643-1.06 \mathrm{MC}-42.738 \mathrm{BD}$ in other fields. 
It is suggested to conduct future studies including depth variation of SS, weed and plant growth parameters which may provide sound information to improve this finding.

\section{ACKNOWLEDGEMENT}

The authors thank the Rajarata University of Sri Lanka (RUSL) and University of Peradeniya for providing the opportunity to make this research project a success and Mr. D.D.P. Arunasiri for the assistance in experimental activities. This research work was funded by University Grants Commission (UGC), Sri Lanka.

\section{REFERENCES}

Bailey, A.C. and Weber. J. (1965). Comparison of methods of measuring shear strength using artificial soils. TRANSACTIONS of the American Society of Agricultural Engineers. 8(2): $153-156,160$.

Bhagat, R.M. (1990). Effect of tillage and residue management on hydro-thermal regime, nutrient uptake and yield of wheat in a river deposit. Soil Tillage Res. 17, 315-326.

Bhagat, R.M. (2003). Rice Lands of South and South East Asia, Some Soil Physical Aspects. Department of Soil Science, CSKHPAU, Palampur, H.P., India. [on line]. [Accessed on 28.07.2014]. Available at: http://users.ictp.it/ pub_off/ lectures/lns018/07Bhagat1.pdf

Burns, C.A., Luna, M., Daniel, R.C., Schmidt, A.J. and Enderin, C.W. (2009). Shear Strength Measurement Benchmarking Tests for K Basin Sludge Stimulants. [on line]. [Assessed on 17.08.2014]. Available at www.pnl.gov/main /publications/external/technical.../PNNL-18479. pdf.

DCS (Department of Census and Statistics). (2015). Paddy Statistics. Colombo Sri Lanka. [On line]. [Accessed on 18.07.2015]. Available at:

http://www.statistics.gov.lk/agriculture/Paddy\% 20Statistics/PaddyStatsPages.htm.

Dharmakeerthi, R.S. (2007). Manual of Soil Sampling and Analysis. pp. 19 - 21. In: Dharmakeerthi, R.S., Indraratne, S.P. and Kumarage, D. (Ed). Special Publication No. 01, Soil Science Society of Sri Lanka.

Dunlap, W. H., Vanden Berg, G. and Hendrick, J. (1966). Comparison of soil shear values obtained with devices of different geometrical shapes. TRANSACTIONS of the American Society of Agricultural Engineers. 9(6), 896 - 900.

Eudoxie, G. D., Phillips, D. and Springer, R. (2012). Surface Hardness as an Indicator of Soil Strength of Agricultural Soils. Open Journal of Soil Science. 2, 341 - 346. doi. org/10.4236/ojss.2012.24040

FMRC (Farm Mechanization Research Centre). (1991). Mechanization survey report. Mahailluppallama: Department of Agriculture, Sri Lanka.

Ghildyal, B.P. and Tripathi, R.P. (1987). Soil Physics. Johan Wiley Eastern Limited, New Delhi, India. 
Grossman, R.B. and Reinsch, T.G. (2002). Bulk density and linear extensibility. pp 201 225. In: Dane, J.H. and Topp, G.C. (Ed) Methods of soil analysis, Part 4. Soil Science Society of America, Madison, WI.

Hillel, D. (2004). Introduction to Environmental Soil Physics. Elsevier, USA.

Hillel, H. (1971). Soil and Water: Physical and processes, Academic Press, New York.

IRRI (International Rice Research Institute). (1994). Soil Physical Properties Measurement and Use in Rice-based Cropping systems. pp 59 - 65. In: Wopereis, M.; Kropff, M.; Boama, J.; Van Wijk, A.; and Woodhead, T. (Ed). International Rice Research Institute, Manila, Philippines.

Jayatissa, D.N. and Wickramasinghe, W.A.M.P. (2010). Final report on Testing Improved Wooden Clog for Weed Control in Row-seeded or Row-planted Paddy Fields, Report submitted to JICA/EAA.

Johnson, C.E., Grisso, R.D., Nichols, T.A. and Bailey, A.C. (1987). Shear measurement for agricultural soils - A review; Transaction of American Society of Agricultural Engineers. 30(4), 935-938.

Lipiec, J. and Hatano, R. (2003). Quantification of Compaction Effects on Soil Physical Properties and Crop Growth. Geoderma. 116, 1-2, 107-136. doi:10.1016/S00167061(03)00097 - 1

Majumdar, S.P. and Singh, R.A. (2002). Analysis of Soil Physical Properties. Agrobios (India), Jodhpur.

Mapa, R.B., Somasiri, S. and Dassanayake, A.R. (2009). Soils of the Dry Zone of Sri Lanka. Morphology, Characterization and Classification. Special Publication No. 7. Soil Science Society of Sri Lanka. Sarvodaya Vishva Lekha, Colombo, Sri Lanka.

Nelson, D.W. and Sommers, L.E. (1982). Total carbon, organic carbon and organic matter. In: Methods of soil analysis. Part 2. $2^{\text {nd }}$ ed. Agronomy No.09, American Society of Agronomy, Madison, WI, USA.

Onyelowe and Chibuzor, K., (2013). Effect of Water Content on the Shear Strength of Amaoba Lateritic Soil. International Journal of Engineering \& Technology Research. 1, 01 10. [on line]. [Assessed on 17.07.2013]. Available at

http://www.iaster.com/uploadfolder/1EffectofWaterContentCopy/1Effect $\% 20$ of $\% 20$ Water $\%$ 20Content-Copy.pdf

Osman, M.S. (1964). The measurement of soil shear strength. Jour, of Terramechanics. l(3), 54-60.

Punyawardane, B.V.R., Bandara, T.M.J., Munasinghe, M.A.K., Banda, N.J. and Pushpakumara, S.M.V. (2003). Agro-ecological Regions of Sri Lanka. Natural Resource Management Center, Department of Agriculture, Peradeniya, Sri Lanka.

Rathnaweera, A.C., Rajapakse, N.N., Ranasinghe, C.J., Thennakooon, T.M.S., Kumara, R.S., Balasooriya, C.P. and Bandara, M.A. (2010). Design of Power Weeder for Low Land Paddy 
Cultivation. In the International Conference on Sustainable Built Environment, Kandy, 13 14 December, 2010.

Rathnayaka, M.R.M.P.K., Kahandage, P.D., Weerasooriya, G.V.T.V. and Bandara, M.H.M.A., (2011). Appropriateness and Required Modification for Existing Machineries in Paddy Production in North Central Province. In: Proceedings of the Undergraduate Research Symposium 2011, Faculty of Agriculture, Rajarata University of Sri Lanka, Anuradhapura, Sri Lanka. pp 44.

Singh, R.A. (1980). Soil physical analysis. Kalyani publishers, New Delhi.

Tilakaratna, H.M. and Tilakaratna, I.G. (2003). Farm mechanization in rice cultivation. Rice congress 2000, pp.157-166. In: Abeysiriwardena, D.S.de Z.; Dissanayake, D.M.N.; Nugaliyadde, L.; (Ed.) Peradeniya: Department of Agriculture, Sri Lanka.

Weerasooriya, G.V.T.V., Jayatissa, D.N. and Rambanda, M. (2015). Bulk soil properties as determinants of the compression strength of puddle lowland paddy soils in Sri Lanka: Tropical Agricultural Research. 26(3), $561-568$.

Wickramasinghe, W.M.A.D.B. (2007). Manual of Soil Sampling and Analysis. pp. 59 - 60. In: Dharmakeerthi, R.S., Indraratne, S.P. and Kumarage, D. (Ed). Special Publication No. 01, Soil Science Society of Sri Lanka.

Young, R.N. and Youssef, A. (1978). Application of vane-cone tests on soil for determination of trafficability. Proceedings of $6^{\text {th }}$ International Conference ISTVS. Vienna, Austria. 2, $667-706$. 